University of Wollongong

Research Online

Faculty of Science, Medicine and Health -

Papers: Part B

Faculty of Science, Medicine and Health

$1-1-2018$

\title{
Hormone-induced spawning of the critically endangered northern corroboree frog Pseudophryne pengilleyi
}

Aimee J. Silla

University of Wollongong, asilla@uow.edu.au

Michael McFadden

Taronga Conservation Society Australia, mm437@uowmail.edu.au

Phillip G. Byrne

University of Wollongong, pbyrne@uow.edu.au

Follow this and additional works at: https://ro.uow.edu.au/smhpapers1

\section{Publication Details Citation}

Silla, A. J., McFadden, M., \& Byrne, P. G. (2018). Hormone-induced spawning of the critically endangered northern corroboree frog Pseudophryne pengilleyi. Faculty of Science, Medicine and Health - Papers: Part B. Retrieved from https://ro.uow.edu.au/smhpapers1/100 


\title{
Hormone-induced spawning of the critically endangered northern corroboree frog Pseudophryne pengilleyi
}

\author{
Abstract \\ Fundamental knowledge of the optimal hormone concentrations required to stimulate amplexus and \\ spawning in breeding pairs of amphibians is currently lacking, hindering our understanding of the \\ proximate mechanisms underpinning mating behaviour. The present study investigated the effects of: (1) \\ the dose of a gonadotropin-releasing hormone analogue (GnRH-A) administered; (2) male-female \\ hormone administration interval; and (3) topical application of GnRH-A, on spawning success in the \\ northern corroboree frog. Administration of GnRH-A at doses of $0.5,1.0$ and $2.0 \mu \mathrm{g} \mathrm{g}-1$ were highly \\ successful, with a significantly greater proportion of hormone-Treated pairs ovipositing (89-100\%) \\ compared with the $0 \mu \mathrm{g} \mathrm{g}-1$ treatment (22\%). Of the hormone-Treated pairs, those receiving $0.5 \mu \mathrm{g}$ \\ g- $1 \mathrm{GnRH}-\mathrm{A}$ exhibited the highest fertilisation success (61\%). Administration of GnRH-A to males and \\ females simultaneously $(0 \mathrm{~h})$ was more effective than injecting males either 48 or $24 \mathrm{~h}$ before the \\ injection of females. Overall, administration of GnRH-A was highly successful at inducing spawning in \\ northern corroboree frogs. For the first time, we also effectively induced spawning following the topical \\ application of $\mathrm{GnRH}-\mathrm{A}$ to the ventral pelvic region. Topical application of $\mathrm{GnRH}-\mathrm{A}$ eliminates the need for \\ specialised training in amphibian injection, and will allow assisted reproductive technologies to be \\ adopted by a greater number of captive facilities globally.

\section{Publication Details} \\ Silla, A. J., McFadden, M. \& Byrne, P. G. (2018). Hormone-induced spawning of the critically endangered \\ northern corroboree frog Pseudophryne pengilleyi. Reproduction, Fertility and Development, 30 (10), \\ 1352-1358.
}


1 Hormone-induced spawning of the critically endangered

2 Northern Corroboree Frog, Pseudophryne pengilleyi

3

4 Aimee J. Silla ${ }^{1^{*}}$, Michael McFadden ${ }^{2}$ and Phillip G. Byrne ${ }^{1}$

$5{ }^{1}$ Centre for Sustainable Ecosystem Solutions, School of Biological Sciences, University of Wollongong,

6 Wollongong, NSW 2522, Australia

$7 \quad{ }^{2}$ Herpetofauna Department, Taronga Conservation Society Australia, PO Box 20, Mosman, NSW 2088

8 Australia

9

10

* Corresponding author.

Email addresses:

AS: aimee.silla@gmx.com

MM: mmcfadden@zoo.nsw.gov

PB: pbyrne@uow.edu.au

Running Head: Hormone-induced spawning of the Northern Corroboree Frog 
35 Abstract

36 Fundamental knowledge of the optimal hormone concentrations required to stimulate amplexus and spawning in breeding pairs of amphibians is currently lacking, hindering our understanding of the proximate mechanisms underpinning mating behaviour. The present study investigated the effects of: 1) GnRH-a dose, 2) male:female hormone administration interval, and 3) topical application of Gonadotropin-releasing hormone analogue ( $\mathrm{GnRH}-\mathrm{a})$, on spawning success in the Northern Corroboree Frog. Administration of GnRH-a at doses of $0.5,1.0$, and $2.0 \mu \mathrm{g} / \mathrm{g}$ were highly successful, with a significantly greater proportion of hormone-treated pairs ovipositing ( $89-100 \%$ ) compared to the $0 \mu \mathrm{g} / \mathrm{g}$ treatment $(22 \%)$. Of the hormone-treated pairs, those receiving $0.5 \mu \mathrm{g} / \mathrm{g}$ exhibited the highest fertilisation success (61\%). Administration of GnRH-a to males and females simultaneously (Ohrs) was more effective than injecting males at either 48 or $24 \mathrm{hrs}$ prior to the injection of females. Overall, administration of GnRH-a was highly successful at inducing spawning in Northern Corroboree Frogs. For the first time, we also effectively induced spawning following the topical application of GnRH-a to the ventral pelvic region. Topical application of GnRH-a eliminates the need for specialised training in amphibian injection, and will allow assisted reproductive technologies to be adopted by a greater number of captive facilities globally. gamete-release, GnRH, LHRH, mating, reproduction, spawning. 


\section{Introduction}

Advances in assisted reproductive technologies (ARTs) have markedly improved the efficiency and sustainability of agricultural animal production. More recently, the value of ARTs for endangered species recovery has been recognised in order to overcome the behavioural impediments to natural mating and fertilisation that captive animals often encounter (Durrant 2009). Recent reports confirm that we are already amidst a sixth mass extinction (Ceballos et al. 2015), with numerous conservation breeding programs established for threatened species globally. These programs aim to maintain genetically viable insurance colonies ex situ, while also providing individuals for population augmentation, translocation and reintroduction in situ. Despite considerable efforts to mimic natural environmental cues, many amphibian conservation breeding programs continue to face difficulties reliably and predictably initiating breeding behaviour in captivity (Kouba et al. 2009). This deficiency threatens the genetic viability of insurance colonies and has limited the generation of largenumbers of individuals for release. Assisted reproductive technologies, such as the hormonal induction of spawning, gamete-release and artificial fertilisation, have the potential to contribute to amphibian conservation by enhancing species propagation, synchronizing breeding events and permitting greater control over the genetic management of insurance colonies.

Exogenous reproductive hormones have been used to successfully induce spawning and gamete-release in a number of anuran (frog and toad) and urodele (newt and salamander) species (Byrne and Silla 2010; Mansour et al. 2011; Silla 2011; Trudeau et al. 2013; Calatayud et al. 2015; Uteshev et al. 2015; Della Togna et al. 2017). The two hormones most commonly employed are human chorionic gonadotropin (hCG) and gonadotropin- releasing hormone (GnRH, also known as luteinizing hormone- releasing hormone; LHRH). The administration of purified hCG mimics the luteinizing hormone (LH) surge required to stimulate final gamete maturation and release (hypophyseal approach; Vu and Trudeau 2016). For most amphibian species, hCG is less effective, and may reflect species specificity in LHreceptor affinities (Silla and Roberts 2012). In contrast, synthetic GnRH-a is structurally similar to the GnRH-1 molecule found in the anterior pre-optic area of the hypothalamus and the median eminence of the amphibian brain (Vu and Trudeau 2016). GnRH-a acts by stimulating the anterior pituitary gland to synthesise and release natural LH (hypothalamic approach; Vu and Trudeau 2016). Administration of GnRH-a has been shown to effectively 
stimulate ovulation and spermiation in a diversity of anurans in the absence of a mating partner (Michael et al. 2004; Silla 2010; Silla 2011; Silla and Roberts 2012; Jacobs et al. 2016). By contrast, the ability of GnRH-a to elicit mating behaviour, and in particular the optimal doses required to stimulate amplexus and spawning, has seldom been tested empirically, hindering our understanding of the proximate mechanisms underpinning mating behaviour in amphibians.

The administration of GnRH-a is typically achieved via intraperitoneal or subcutaneous injection. However, amphibians also afford a unique opportunity to develop methods for the topical application of exogenous hormones (epicutaneous administration) due to their highly permeable, hypervascularised skin surfaces. The ability to induce spermiation through the topical application of GnRH-a has previously been tested in American Toads (Bufo americanus) and Gulf Coast Toads (Incilius valliceps), with varying degrees of success (Obringer et al. 2000; Rowson et al. 2001). To date, no attempt has been made to employ these protocols to induce ovulation or spawning in amphibians. Refining protocols for the topical application of GnRH-a would be of enormous benefit to amphibian conservation because it would eliminate the need for specialised training in amphibian injection and allow ARTs to be adopted by a greater number of captive facilities.

The northern corroboree frog (Pseudophryne pengilleyi) is considered one of Australia's most threatened vertebrates, listed as Critically Endangered by state and federal governments, and Endangered by the IUCN (McFadden et al. 2016). The species has been the focus of an intensive captive breeding and reintroduction program since 2003, established as a partnership between the Taronga Conservation Society Australia (TCSA), Tidbinbilla Nature Reserve and the NSW Office of Environment and Heritage (OEH) (McFadden et al. 2016). Although northern corroboree frogs have been bred successfully in captivity for a number of years, a proportion of gravid females fail to spawn annually, reducing the reproductive potential of captive colonies. Additionally, captive populations display strong mating biases with less than a third of available males contributing to mating success. Over time, such captive mating biases may lead to a loss of genetic variation and adaptive potential that could compromise re-introduction success.

The present study aimed to empirically test protocols to hormonally induce spawning behaviour in the critically endangered northern corroboree frog, Pseudophryne pengilleyi. Specific objectives were to investigate: 1) the effect of GnRH-a dose, 2) the effect of male:female hormone administration interval, and 3) the effect of topical application of 
GnRH-a, on spawning success. The percentage of pairs ovipositing, number of eggs oviposited, and percentage fertilisation were determined for each experiment.

\section{Methods}

\section{Ethics Statement}

All procedures were conducted following evaluation and approval by the Taronga Conservation Society Australia's Animal Ethics Committee (protocol numbers 3b/08/14 and $3 a / 11 / 16)$.

\section{Study Species}

The northern corroboree frog (Pseudophryne pengilleyi) is a small (25-30mm snout-vent length), terrestrial frog easily recognised by longitudinal black and lime-green/yellow dorsal colouration (Figure 1a). The species is restricted to areas above $850 \mathrm{~m}$ altitude in the Brindabella and Fiery ranges of New South Wales and the Australian Capital Territory in south-eastern Australia. The region experiences an average annual rainfall of 1,200 $\mathrm{mm}$ and snowfall at higher elevations during winter. Breeding in this species commences in late austral summer and continues until early autumn. Male P.pengilleyi construct shallow terrestrial nests in isolated frost-hollow grasslands, narrow seeps, and open bogs that are subject to seasonal inundation (Osborne 1991; Scheele et al. 2017). Females oviposit a small clutch of between 16 - 40 eggs (mean $=24.0$, Osborne 1991), though captive females have been recorded ovipositing up to 59 eggs (range $=17-59$, mean $=35.90 \pm 1.01, n=79$; unpublished data). Fertilised eggs undergo intracapsular embryonic development, which is typically suspended at Gosner Stage 26-28. In the field, terrestrial embryos may remain in suspended development for several weeks until heavy autumn rainfall floods the nest and hypoxia triggers tadpoles to hatch into temporary pools (Osborne 1991). This reproductive mode (terrestrial egg mass with aquatic free-living larvae) is characteristic of the majority of species in the genus Pseudophryne (Watson and Martin 1973).

\section{Animal husbandry}

Northern corroboree frogs were maintained in an isolated, biosecurity facility located at Taronga Zoo, Mosman, NSW, Australia. Internal lighting within the facility was controlled using a weatherproof light sensitive switch (HPM, NSW, Australia) set to simulate local 
photoperiod. Lighting was provided using fluorescent tubes (10.0 UV-B, Reptisun, Germany) suspended approximately $36 \mathrm{~cm}$ above each shelf, resulting in $20-30 \mu \mathrm{W} / \mathrm{cm}^{2} \mathrm{UV}-\mathrm{B}$ at the substrate floor of each enclosure. Ambient temperature within the facility was cycled annually to reflect seasonal changes in the average climatic conditions experienced in the subalpine areas where the species naturally occurs. Temperatures ranged from $5-20^{\circ} \mathrm{C}$, including a 6-week hibernation period. Programmed temperatures were at a maximum during the breeding season, when frogs were maintained on a $20^{\circ} \mathrm{C} / 17^{\circ} \mathrm{C}$ day/ night temperature cycle. Outside of the breeding season, male and female northern corroboree frogs were communally housed in same sex groups in ventilated, clear plastic terraria $(28 \mathrm{~cm} \mathrm{~L} \times 17 \mathrm{~cm}$ $\mathrm{W} \times 18 \mathrm{~cm} \mathrm{H}$; 4-6 individuals per. terrarium). Each terrarium contained a layer of aquarium gravel (particle size $\sim 4 \mathrm{~mm}$ ) approximately two $\mathrm{cm}$ deep, in addition to a layer of hydrated sphagnum moss approximately $5 \mathrm{~cm}$ deep covering half of the enclosure floor. Holes $(3 \mathrm{~mm}$ D) were drilled in the base of each terrarium for drainage. Enclosure substrates were sprayed with reverse osmosis (RO) water twice weekly to break down and remove excrement and detritus. Frogs were fed a diet of 6-9 day old hatchling crickets (Acheta domestica; 15-20 crickets per. individual) once every five days. Crickets were dusted with calcium powder (Calcium with Vit. $\mathrm{D}_{3}$, Rep-Cal Research Labs, United States) prior to every feed and a multivitamin supplement (Herptivite, Rep-Cal Research Labs, United States) every alternate feed.

\section{Experiment 1: The effect of GnRH-a dose on spawning success}

To determine the effect of GnRH-a dose on spawning success, 36 male-female pairs were allocated to one of four experimental treatments; $0.0,0.5,1.0$, or $2.0 \mu \mathrm{g} / \mathrm{gram}$ body weight GnRH-a (Leuprorelin acetate; Lucrin $\left.{ }^{\circledR}\right)(\mathrm{n}=9$ pairs per treatment). All frogs were sexually mature (5-11 years of age) and ranged in weight from 1.39-4.00 grams. The male/female body mass ratio of each pair ranged from $53.82-74.52 \%($ mean \pm sem $=61.12 \pm 0.89)$ and the body mass of males and females did not differ significantly between treatment groups (one-way ANOVA male mass: $\mathrm{F}_{3,32}=0.042, p=0.988$; female mass: $\mathrm{F}_{3,32}=0.676, p=$ $0.573)$.

One week prior to hormone administration, males were removed from communal housing and moved into individual terraria $(28 \mathrm{~cm} \mathrm{~L} \times 17 \mathrm{~cm} \mathrm{~W} \times 18 \mathrm{~cm} \mathrm{H})$ containing substrates as described above (see section 2.3 Animal husbandry). This was done in order to provide each 
male with the opportunity to establish a nest site prior to introducing the female. Individuals within each male-female pair were weighed and administered a single hormone dose corresponding to their experimental treatment. Hormones were diluted in $100 \mu \mathrm{L}$ of Simplified Amphibian Ringer (SAR; $113 \mathrm{mM} \mathrm{NaCl}, 2 \mathrm{mM} \mathrm{KCl}, 1.35 \mathrm{mM} \mathrm{CaCl} 2,1.2 \mathrm{mM}$ NaHCO3) and administered via subcutaneous injection into the dorsal lymph sac (Figure 1b). Three weeks after hormone administration, terraria were searched for the presence of eggs, and the number of eggs oviposited, and fertilisation success, scored. In the absence of eggs, the male-female pair was categorised as unresponsive. Experiment 1 was conducted from April 10 to May 8, 2014.

\section{Experiment 2: The effect of male:female hormone administration interval on spawning} success

To determine the effect of hormone administration interval on spawning success, males were administered GnRH-a at one of three time periods (48, 24, or $0 \mathrm{hrs})$ prior to the administration of GnRH-a to females ( 27 male-female pairs, $n=9$ per treatment). All frogs were sexually mature (5-12 years of age) and ranged in weight from $1.34-3.90$ grams. The male/female body mass ratio of each pair ranged from $48.20-68.83 \%$ (mean \pm sem $=56.56$ $\pm 0.87)$ and the body mass of males and females did not differ significantly between treatment groups (one-way ANOVA male mass: $\mathrm{F}_{2,24}=0.021, p=0.979$; female mass: $\mathrm{F}_{2,24}$ $=0.191, p=0.827)$.

One week prior to hormone administration, males were removed from communal housing and moved into individual terraria $(28 \mathrm{~cm} \mathrm{~L} \times 17 \mathrm{~cm} \mathrm{~W} \times 18 \mathrm{~cm} \mathrm{H})$ containing substrates as described above (see section 2.3 Animal husbandry). Males were removed from their enclosures, weighed and administered a single dose of $0.5 \mu \mathrm{g} / \mathrm{g} \mathrm{GnRH}-\mathrm{a}$ either 48,24 , or 0 hrs prior to the introduction of freshly injected females. As with the males, all females received a single injection of $0.5 \mu \mathrm{g} / \mathrm{g} \mathrm{GnRH}-\mathrm{a}$ (diluted in $100 \mu \mathrm{L}$ of SAR) administered via subcutaneous injection into the dorsal lymph sac (Figure 1b). Three weeks after hormone administration, terraria were searched for the presence of eggs, and the number of eggs oviposited, and fertilisation success, scored. In the absence of eggs, the male-female pair was categorised as unresponsive. Experiment 2 was conducted from March 31 to April 27, 2015. 
232 To determine the effect of topical application of GnRH-a on spawning success, 37 male-

233 female pairs were allocated to one of three experimental treatments $(n=11-13$ pairs per

234 treatment; 0,25 or $50 \mu \mathrm{g} / \mathrm{g}$ GnRH-a). All frogs were sexually mature (5-14 years of age) and

235 ranged in weight from $1.45-4.39$ grams. The male/female body mass ratio of each pair 236 ranged from $46.47-72.09 \%($ mean \pm sem $=54.54 \pm 0.84)$ and the body mass of males and

237 females did not differ significantly between treatment groups (one-way ANOVA male mass:

$238 \quad \mathrm{~F}_{2,33}=0.177, p=0.839$; female mass: $\mathrm{F}_{2,33}=0.215, p=0.808$ ).

239 As with experiments 1 and 2 detailed above, male frogs were removed from communal 240 housing and moved into individual terraria $(28 \mathrm{~cm} \mathrm{~L} \times 17 \mathrm{~cm} \mathrm{~W} \times 18 \mathrm{~cm} \mathrm{H})$ one week prior to 241 the introduction of females. Individuals within each male-female pair were weighed and 242 administered a single hormone dose corresponding to their experimental treatment $(0,25$ or $24350 \mu \mathrm{g} / \mathrm{g} \mathrm{GnRH}-\mathrm{a} ; \mathrm{n}=11,13$ and 13, respectively). Hormones were diluted in $100 \mu \mathrm{L}$ of 244 distilled water and administered dermally via drop-wise topical application onto the ventral 245 abdominal surface (Figure 1c). Three weeks after hormone administration, terraria were searched for the presence of eggs, and the number of eggs oviposited, and fertilisation success, scored. In the absence of eggs, the male-female pair was categorised as unresponsive. Experiment 3 was conducted from March 23 to April 20, 2017.

\section{Statistical Analyses}

251

252

253

254

255

256

257

258

The numbers of male-female pairs ovipositing were compared between treatment groups in each experiment using two-tailed Fisher's exact tests. One-way analyses of variance (ANOVAs) were used to test for statistical differences in the mean number of eggs oviposited or percent fertilisation, between experimental treatments. Comparisons among treatment means were conducted using Tukey-Kramer Honestly Significant Difference (HSD) post hoc tests. To verify homogeneity of variances, Levene's tests were performed. If variances were unequal, Kruskal-Wallis tests (KW) were conducted, and post hoc treatment comparisons were made using Wilcoxon matched-pair tests. All statistical analyses were performed using JMP Pro 11.0.0 software package (SAS Institute Inc. North Carolina, USE). For all analyses, statistical significance was accepted at $\mathrm{P}<0.05$. 
263 Results

264 Experiment 1: The effect of GnRH-a dose on spawning success

265 The number of male-female pairs ovipositing in response to the administration of $0.5,1.0$, or $2662.0 \mu \mathrm{g} / \mathrm{g}$ GnRH-a was significantly greater than the number of pairs ovipositing in response 267 to the $0 \mu \mathrm{g} / \mathrm{g} \mathrm{GnRH}-\mathrm{a}$ treatment (no hormone stimulation)( Fisher's Exact Tests, $P<0.05$;

268 Table 1). Similarly, the total number of eggs laid in response to GnRH-a differed 269 significantly among dose treatments (one-way ANOVA, $\mathrm{F}_{3,32}=7.186, p=0.0008$ ), with 270 pairs receiving $0.5,1.0$, or $2.0 \mu \mathrm{g} / \mathrm{g} \mathrm{GnRH}$-a producing a significantly greater number of eggs than pairs receiving $0.0 \mu \mathrm{g} / \mathrm{g}$ GnRH-a (Tukey-Kramer HSD, $P<0.05$; Table 1). Percent fertilisation was calculated for all pairs that oviposited. Overall, mean percent fertilisation also differed significantly among treatment groups (Kruskal Wallice test, $\chi^{2}=9.051, p=$ 0.0286), with percent fertilisation significantly higher in the $0.0 \mu \mathrm{g} / \mathrm{g} \mathrm{GnRH}$-a dose treatment compared with the 1.0 and $2.0 \mu \mathrm{g} / \mathrm{g}$ dose treatments (Tukey-Kramer HSD, $P<0.05$; Table 1 ). Mean percent fertilisation of clutches in the $0.5 \mu \mathrm{g} / \mathrm{g}$ GnRH-a dose treatment was not significantly different from any of the remaining doses $(0.0,1.0 \& 2.0 \mu \mathrm{g} / \mathrm{g}$ GnRH-a; TukeyKramer HSD, $P>0.05$; Table 1).

Experiment 2: The effect of male:female hormone administration interval on spawning success

Hormone administration interval did not significantly effect the number of pairs that oviposited (Fisher's Exact Tests, $P>0.05$ ), or the number of eggs laid (Kruskal Wallice test, $\chi^{2}=0.621, p=0.733$; Table 2). Similarly, mean percent fertilisation did not differ significantly among treatment groups (Kruskal Wallice test, $\chi^{2}=5.584, p=0.0613$; Table 2). However, Wilcoxon matched-pair post-hoc tests indicated that mean percent fertilisation was significantly higher in the $0-\mathrm{hr}$ treatment compared to 24 -hrs $(64 \%$ and $25 \%$, respectively; Table 2). 
The number of male-female pairs ovipositing in response to the topical administration of 25 $\mu \mathrm{g} / \mathrm{g}$ GnRH-a was significantly greater than the number of pairs ovipositing in response to the $0 \mu \mathrm{g} / \mathrm{g}$ GnRH-a dose treatment (Fisher's Exact Test, $P=0.0377$ ). In contrast, the number of pairs ovipositing in response to $50 \mu \mathrm{g} / \mathrm{g}$ GnRH-a, was not significantly different from either the $0 \mu \mathrm{g} / \mathrm{g}$ or $25 \mu \mathrm{g} / \mathrm{g}$ dose treatments (Fisher's Exact Tests, $P<0.05$; Table 3). Similarly, the number of eggs laid in response to GnRH-a differed significantly among dose treatments (one-way ANOVA, $\mathrm{F}_{2,34}=3.540, p=0.040$ ), with pairs receiving $25 \mu \mathrm{g} / \mathrm{g}$ GnRH-a producing a significantly greater number of eggs than the $0 \mu \mathrm{g} / \mathrm{g} \mathrm{GnRH}$-a dose treatment (Tukey-Kramer HSD, $P<0.05$; Table 3). The number of eggs laid in response to the topical administration of $50 \mu \mathrm{g} / \mathrm{g}$ GnRH-a was not significantly different from either the $0 \mu \mathrm{g} / \mathrm{g}$ or 25 $\mu \mathrm{g} / \mathrm{g}$ dose treatments (Tukey-Kramer HSD, $P>0.05$; Table 3). Percent fertilisation was calculated for all pairs that oviposited, with mean percent fertilisation statistically similar among treatment groups (one-way ANOVA, $\mathrm{F}_{2,18}=0.517, p=0.605$; Table 3 ).

\section{Discussion}

Assisted reproductive technologies have enormous potential to enhance captive breeding and reintroduction programs by improving species propagation and permitting greater control over the genetic management of insurance colonies. To date empirical studies have predominantly focused on quantifying the effects of exogenous hormone administration on gamete-release in individuals (in the absence of a mating partner), as a precursor to gametestorage and artificial fertilisation (AF, also known as in vitro fertilisation, IVF) (Browne et al. 2006; Byrne and Silla 2010; Silla 2011; Silla 2013; Uteshev et al. 2015; Della Togna et al. 2017). Fundamental knowledge of the optimal hormone concentrations required to stimulate amplexus and spawning in breeding pairs of amphibians is substantially lacking by comparison, hindering our understanding of the proximate mechanisms underpinning mating behaviour in amphibians. In the present study we aimed to empirically test protocols to hormonally induce spawning behaviour in the critically endangered northern corroboree frog. Specifically, we investigated the effects of 1) GnRH-a dose, 2) male:female hormone administration interval, and 3) topical application of GnRH-a, on spawning success. Results from this study showed that the administration of GnRH-a at doses of 0.5 $\mu \mathrm{g} / \mathrm{g}, 1 \mu \mathrm{g} / \mathrm{g}$, and $2 \mu \mathrm{g} / \mathrm{g}$ body weight were highly successful at inducing spawning, with a significantly greater proportion of hormone treated pairs ovipositing (72-100\%) compared to 
pairs in the $0 \mu \mathrm{g} / \mathrm{g} \mathrm{GnRH}-\mathrm{a}$ dose treatment (22\%). Our results are consistent with those of previous studies on northern leopard frogs (Lithobates pipiens) that report a significant increase in the spawning success of hormone treated frogs (42-100\% and $88-89 \%$, respectively) compared with untreated animals, which failed to spawn (Trudeau et al. 2010; Trudeau et al. 2013). Similar findings have also been reported in captive rocky mountain boreal toads (Anaxryus boreas boreas), where hormone administration effectively doubled the proportion of spawning pairs (from 17\% to 33\%) (Calatayud et al. 2017). Interestingly, previous studies inducing spawning in amphibians have all administered $\mathrm{GnRH}-\mathrm{a}$ in combination with other reproductive hormones, including hCG and dopamine antagonists (metoclopramide, pimozide \& domperidone) (Trudeau et al. 2010; Trudeau et al. 2013; Calatayud et al. 2017). The present study is the first to demonstrate that GnRH-a alone can induce $100 \%$ of male-female pairs to spawn at doses of either 0.5 or $2 \mu \mathrm{g} / \mathrm{g}$ and highlights the importance of establishing dose- response curves for individual hormones.

The fertilisation success of clutches oviposited in the present study also differed significantly according to the GnRH-a dose administered. Male-female pairs in the $0 \mu \mathrm{g} / \mathrm{g}$ GnRH-a dose treatment exhibited the greatest percentage fertilisation (97\%), however it is important to note that only two pairs oviposited and the fertilisation success of untreated animals may vary with additional replication. Of the hormone treated pairs ovipositing $(n=8$ 9 per treatment), those injected with $0.5 \mu \mathrm{g} / \mathrm{g}$ GnRH-a exhibited the greatest percentage fertilisation (61\%), while frogs in the higher dose treatments (1 \& $2 \mu \mathrm{g} / \mathrm{g} \mathrm{GnRH}-\mathrm{a})$ displayed low mean fertilisation success $(<22 \%)$. One explanation for the reduced fertilisation success observed in the higher dose treatments is that oocytes underwent a process of over-ripening. Over-ripening results from the aging and deterioration of oocytes retained for an extended period within the coelomic cavity of a female post ovulation (Bromage et al. 1994; Silla 2011). Oocyte over-ripening may have occurred in the higher dose treatments if oocyte maturation and ovulation was stimulated too quickly, resulting in the retention of oocytes prior to amplexus and fertilisation. This explanation is consistent with the observation that embryos oviposited within the higher dose treatments were often scattered or clumped in small groups rather than deposited in a discrete, well-defined nest.

Interestingly, amphibian species appear to vary considerably in their sensitivity to GnRH-a administration (Silla and Roberts 2012), despite the general conservation of the structure and function of GnRH among vertebrates (Gore 2002). If doses of GnRH-a administered are too low for a given species, they may induce the upregulation of GnRH receptors without a corresponding change in LH synthesis and release (Conn 1986; Gore 
2002), resulting in incomplete oocyte maturation, reduced spawning rates and/or fertilisation success. As GnRH-a doses administered are increased, nearing optimal concentrations, upregulation of GnRH receptors continues, receptor numbers are elevated and the tissue responds with the LH surge required to stimulate final oocyte maturation and ovulation (Conn 1986; Gore 2002). If optimal GnRH-a doses are exceeded, oocyte over-ripening may occur resulting in a reduction of oocyte quality and diminished fertilisation success (Silla 2011). Interspecific variation in the comparative efficacy of GnRH administration, and therefore optimal dose, is unlikely to be driven by species-specific differences in the structure of natural GnRH, as the amino acid sequences of these molecules are highly conserved across all vertebrate species (Gore 2002). However, given the phylogenetic diversity of anurans and the diversity of reproductive modes they exhibit, it is reasonable to expect interspecific variance, not in the GnRH molecules themselves, but in the timing and concentration of GnRH released. Gaining knowledge of the optimal GnRH doses required to stimulate amplexus and spawning across a diversity of species will therefore further our understanding of the evolution of the proximate mechanisms controlling mating behaviour in amphibians.

An alternative approach to the injection of GnRH-a is the epicutaneous administration of the hormone directly to the ventral abdominal skin surface (topical application). The topical application of GnRH-a was initially tested in male American toads to induce spermiation with poor success (22\% spermiation response)(Obringer et al. 2000). However, further protocol refinement using higher hormone doses led to the successful induction of spermiation in both American toads and gulf coast toads (75\% spermiation response) (Rowson et al. 2001). The present study tested for the first time the efficacy of GnRH-a applied topically to the ventral abdominal surface of male and female frogs to induce spawning. Topical administration protocols were highly successful, with $77 \%$ of male-female pairs ovipositing in response to a dose of $25 \mu \mathrm{g} / \mathrm{g} \mathrm{GnRH}-\mathrm{a}$. This is the first demonstration that topical application of reproductive hormones can induce spawning in an amphibian. Amphibians possess highly vascularised, permeable ventral pelvic surfaces that enable the rapid absorption of water and low molecular weight compounds (Toledo and Jared 1993). This is particularly true for terrestrial amphibians, which exhibit a greater intensity of cutaneous vascularisation in the pelvic region compared with aquatic species (Toledo and Jared 1993), making them ideal candidates for the topical application of reproductive hormones.

Incorporating ARTs into existing conservation breeding programs has the potential to enhance species propagation, allow the synchronisation of breeding events, and increase 
genetic diversity and adaptive potential of the offspring generated. Furthermore, incorporating ARTs enables better control over breeding designs and provides an opportunity for selective breeding of particular genotypes. As a result, ARTs are being increasingly employed by captive facilities to compliment traditional breeding methods and enhance species recovery (Silla et al. 2015). At present, a vast number of CBPs for threatened amphibians are yet to benefit from the implementation of ARTs. One reason for this is that a disproportionate number of threatened amphibian species originate from developing countries within Neotropical, Afrotropical and Indomalayan regions (collectively harbouring $>82 \%$ of rapidly declining amphibians)(Stuart et al. 2004). CBPs in these locations often have limited resources and lack veterinary capacity or personnel with expertise in amphibian injection. The topical hormone administration protocols developed in the present study have enormous potential to increase the number of captive facilities globally adopting ARTs. Such cost effective protocols that eliminate the need for specialised training (such as animal injection or gamete-collection) are urgently needed to assist amphibian species recovery.

\section{Conclusions}

Assisted reproductive technologies have enormous potential to contribute to amphibian conservation breeding programs by increasing species propagation, synchronizing breeding events and permitting greater control over the genetic management of insurance colonies. Here we demonstrate that GnRH-a can be effectively used to induce spawning in the critically endangered northern corroboree frog, with $100 \%$ of male-female pairs ovipositing in response to an optimal dose of $0.5 \mu \mathrm{g} / \mathrm{g}$. In a world first, we also effectively induced spawning following the topical application of GnRH-a to the ventral pelvic region. Topical application of reproductive hormones eliminates the need for specialised training in amphibian injection. Refinement of these protocols will therefore allow ARTs to be adopted by a greater number of captive facilities globally to enhance threatened species recovery.

\section{Acknowledgements}

We acknowledge staff from Taronga Conservation Society Australia's Herpetofauna division, in particular Caitlin Gilchrist, Cara Anger and Emma Bembrick, for assistance with amphibian husbandry. We also acknowledge the support of NSW Office of Environment and Heritage (OEH) Threatened Species Officer, Dr David Hunter and members of the Corroboree Frog Recovery Team. This study was funded by the NSW Environmental Trust (grant no. 2012/RD/0105) and Australian Research Council (Linkage Grant LP140100808). 


\section{Authors' contributions}

AS, PB and MM designed the experiment and collected the data. AS and PB performed the statistical analyses. AS wrote the manuscript with input from all authors.

\section{Competing interests}

The authors declare that there are no competing interests.

\section{References}

Bromage, N., Bruce, M., Basavaraja, N., Rana, K., Shields, R., Young, C., Dye, J., Smith, P., Gillespie, M., and Gamble, J. (1994) Egg Quality Determinants in Finfish The Role of Overripening with Special Reference to the Timing of Stripping in the Atlantic Halibut Hippoglossus hippoglossus. Journal of the World Aquaculture Society 25(1), 13-21

Browne, R., Seratt, J., Vance, C., and Kouba, A. (2006) Hormonal priming, induction of ovulation and in-vitro fertilization of the endangered Wyoming toad (Bufo baxteri). Reprod Biol Endocrinol 4

Byrne, P., and Silla, A. (2010) Hormonal induction of gamete release, and in-vitro fertilisation, in the critically endangered Southern Corroboree Frog, Pseudophryne corroboree. Reprod Biol Endocrinol 8

Calatayud, N.E., Langhorne, C.J., Mullen, A.C., Williams, C.L., Smith, T., Bullock, L., Kouba, A.J., and Willard, S.T. (2015) A hormone priming regimen and hibernation affect oviposition in the boreal toad (Anaxyrus boreas boreas). Theriogenology 84(4), 600-607

Calatayud, N.E., Mullen, A.K., and Langhorne, C.J. (2017) Induction of Reproductive Behaviors by Exogenous Hormones in Captive Southern Rocky Mountain Boreal Toads, Anaxyrus boreas boreas. bioRxiv, 131763

Ceballos, G., Ehrlich, P.R., Barnosky, A.D., García, A., Pringle, R.M., and Palmer, T.M. (2015) Accelerated modern human-induced species losses: Entering the sixth mass extinction. Science Advances 1(5)

Conn, P.M. (1986) The molecular basis of gonadotropin-releasing hormone action. Endocrine reviews 7(1), 3-10

Della Togna, G., Trudeau, V.L., Gratwicke, B., Evans, M., Augustine, L., Chia, H., Bronikowski, E.J., Murphy, J.B., and Comizzoli, P. (2017) Effects of hormonal stimulation on the concentration and quality of excreted spermatozoa in the critically endangered Panamanian golden frog (Atelopus zeteki). Theriogenology 91, 27-35

Durrant, B.S. (2009) The importance and potential of artificial insemination in CANDES (companion animals, non-domestic, endangered species). Theriogenology 71(1), 113-122

Gore, A.C. (2002) 'GnRH: the master molecule of reproduction.' (Springer Science \& Business Media) 
Jacobs, L.E., Robertson, J.M., and Kaiser, K. (2016) Variation in male spermiation response to exogenous hormones among divergent populations of Red-eyed Treefrogs. Reproductive Biology and Endocrinology 14(1), 83

Kouba, A.J., Vance, C.K., and Willis, E.L. (2009) Artificial fertilization for amphibian conservation: current knowledge and future considerations. Theriogenology $\mathbf{7 1}$

Mansour, N., Lahnsteiner, F., and Patzner, R.A. (2011) Collection of gametes from live axolotl, Ambystoma mexicanum, and standardization of in vitro fertilization. Theriogenology 75(2), 354-361

McFadden, M., Hunter, D., Evans, M., Scheele, B., Pietsch, R., and Harlow, P. (2016) Re-introduction of the northern corroboree frog in the Northern Brindabella Mountains, New South Wales, Australia. Global Re-introduction Perspectives: 2016. Case-studies from around the globe. Gland, Switzerland: IUCN/SSC Re-introduction Specialist Group and Abu Dhabi, UAE: Environment Agency. 2016, 35-39

Michael, S., Buckley, C., Toro, E., Estrada, A., and Vincent, S. (2004) Induced ovulation and egg deposition in the direct developing anuran Eleutherodactylus coqui. Reprod Biol Endocrinol 2

Obringer, A.R., O'Brien, J.K., Saunders, R.L., Yamamoto, K., Kikuyama, S., and Roth, T.L. (2000) Characterization of the spermiation response, luteinizing hormone release and sperm quality in the American Toad (Bufo americanus) and the endangered Wyoming Toad (Bufo baxteri). Reprod Fert Develop 12

Osborne, W.S. (1991) 'The biology and management of the Corroboree Frog (Pseudophryne corroboree) in NSW.' (Species management report number 8. NSW National Parks and Wildlife Service)

Rowson, A.D., Obringer, A.R., and Roth, T.L. (2001) Non-invasive treatments of luteinizing hormonereleasing hormone for inducing spermiation in American (Bufo americanus) and Gulf Coast (Bufo valliceps) toads. Zoo biology 20(2), 63-74

Scheele, B.C., Hunter, D.A., Brannelly, L.A., Skerratt, L.F., and Driscoll, D.A. (2017) Reservoir-host amplification of disease impact in an endangered amphibian. Conservation Biology 31(3), 592-600

Silla, A. (2011) Effect of priming injections of luteinizing hormone-releasing hormone on spermiation and ovulation in Gunther's toadlet, Pseudophryne guentheri. Reprod Biol Endocrinol 9

Silla, A.J. (2010) Effects of luteinizing hormone-releasing hormone and arginine-vasotocin on the sperm-release response of Günther's Toadlet, Pseudophryne guentheri. Reproductive Biology and Endocrinology 8:139

Silla, A.J. (2013) Artificial fertilisation in a terrestrial toadlet (Pseudophryne guentheri): effect of medium osmolality, sperm concentration and gamete storage. Reproduction, Fertility and Development 25(8), 1134-1141

Silla, A.J., Keogh, L.M., and Byrne, P.G. (2015) Antibiotics and oxygen availability affect the shortterm storage of spermatozoa from the critically endangered booroolong frog, Litoria booroolongensis. Reproduction, Fertility and Development 27(8), 1147-1153 
Silla, A.J., and Roberts, J.D. (2012) Investigating patterns in the spermiation response of eight Australian frogs administered human chorionic gonadotropin (hCG) and luteinizing hormonereleasing hormone (LHRHa). Gen Comp Endocr 179

Stuart, S.N., Chanson, J.S., Cox, N.A., Young, B.E., Rodrigues, A.S., Fischman, D.L., and Waller, R.W. (2004) Status and trends of amphibian declines and extinctions worldwide. Science 306

Toledo, R.C., and Jared, C. (1993) Cutaneous adaptations to water balance in amphibians. Comparative Biochemistry and Physiology Part A: Physiology 105(4), 593-608

Trudeau, V.L., Schueler, F.W., Navarro-Martin, L., Hamilton, C.K., Bulaeva, E., Bennett, A., Fletcher, W., and Taylor, L. (2013) Efficient induction of spawning of Northern leopard frogs (Lithobates pipiens)during and outside the natural breeding season. Reproductive Biology and Endocrinology 11(1), 14

Trudeau, V.L., Somoza, G.M., Natale, G.S., Pauli, B., Wignall, J., Jackman, P., Doe, K., and Schueler, F.W. (2010) Hormonal induction of spawning in 4 species of frogs by coinjection with a gonadotropin-releasing hormone agonist and a dopamine antagonist. Reprod Biol Endocrinol 16

Uteshev, V., Kaurova, S., Shishova, N., Stolyarov, S., Browne, R., and Gakhova, E. (2015) In vitro fertilization with hormonally induced sperm and eggs from sharp-ribbed newts Pleurodeles waltl. Russian Journal of Herpetology 22(1)

Vu, M., and Trudeau, V.L. (2016) Neuroendocrine control of spawning in amphibians and its practical applications. General and comparative endocrinology 234, 28-39

Watson, G.F., and Martin, A.A. (1973) Life History, larval morphology and relationships of Australian Leptodactylid frogs. Transactions of the Royal Society of South Australia 97(1), 33-45 


\section{Figure and table captions}

Figure one: A) adult northern corroboree frog, P. pengilleyi; B) subcutaneous injection of reproductive hormones into the dorsal lymph sac; $C$ ) topical administration of reproductive hormones onto the ventral abdominal surface.

570

571 Table one: The effect of GnRHa dose on spawning success.

Data shown are the number of pairs ovipositing/total number of pairs, or mean \pm SEM ( $n=9$ per. treatment). Data were analysed using Fisher's Exact Tests (pairs ovipositing), one-way ANOVA (total eggs) or Kruskal Wallice Test (percent fertilisation). Letters displayed are the result of post-hoc tests. Within a row, treatments that share a letter are not significantly different $(P>0.05)$. See methods for details of all statistical analyses.

Table two: The effect of injection interval between the administration of GnRHa to males and females on spawning success.

580 Data shown are the number of pairs ovipositing/total number of pairs, or mean $\pm S E M(n=9$ per. treatment). Data were analysed using Fisher's Exact Tests (pairs ovipositing), or Kruskal Wallice Tests (total eggs, percent fertilisation). Letters displayed are the result of post-hoc tests. Within a row, treatments that share a letter are not significantly different $(P>0.05)$. See methods for details of all statistical analyses.

586 Table three: The effect of topical application of GnRHa on spawning success.

587 Data shown are the number of pairs ovipositing/total number of pairs, or mean \pm SEM ( $n=11-13$ per. treatment). 